\title{
Construirse como sujeto ético para una vida verdadera. Las propuestas de Pierre Hadot, Michel Foucault y François Jullien
}

\author{
Luis Roca Jusmet \\ Universitat Autònoma de Barcelona \\ lroca13@gmail.com
}

Fecha de recepción: 29-6-2021

Fecha de aceptación: 29-7-2021

\section{Resumen}

Este trabajo analiza el hilo conductor que va de Pierre Hadot a François Jullien pasando por Michel Foucault, y que se sostiene en el papel de la filosofía como transformador de sí para alcanzar una vida verdadera. Hadot y Foucault buscan referentes en las escuelas antiguas grecorromanas, mientras François Jullien lo hace en la sabiduría tradicional china. Pero es en todos los casos una búsqueda del pasado para volver al presente y así actualizar este diálogo con los antiguos. Pierre Hadot hablará de la filosofía como ejercicio espiritual, Michel Foucault como del cuidado de sí y François Jullien como del aprendizaje del vivir existiendo. La continuidad está en esta voluntad de hacer de la filosofía un instrumento para construirse como sujeto ético, cuyo resultado es otro modo de vida, una vida verdadera.

Palabras clave: sujeto ético; transformación de sí; Pierre Hadot; Michel Foucault; François Jullien; vida verdadera

Abstract. Constructing oneself as an ethical subject for a true life: The proposals of Pierre Hadot, Michel Foucault and François Jullien

This work analyses the line of thought that stretches from Pierre Haddot to Francois Jullien, by way of Michel Foucault; one that sees the role of philosophy as a transformer of the self to achieve a true life. Hadot and Foucault look for examples in ancient Greco-Roman schools, while François Jullien looks for them in traditional Chinese wisdom. But in all cases it is a search of the past to return to the present and thus to update this dialogue with the old. Pierre Hadot talks of philosophy as a spiritual exercise, Michel Foucault as care of the self and François Jullien as an apprenticeship of life being lived. Continuity lies in this will to make philosophy an instrument to construct oneself as an ethical subject, the result of which is another way of life, a true life.

Keywords: ethical subject; transformation of the self; Pierre Hadot; Michel Foucault; François Jullien; true life 


\section{Sumario \\ 1. Introducción 4. François Jullien: vivir existiendo \\ 2. Pierre Hadot: la filosofía como forma de vida \\ 5. Construir un sujeto ético para «una vida verdadera» \\ 3. Michel Foucault: el cuidado de sí Referencias bibliográficas \\ para otra vida}

La verdadera vida está ausente.

(Arthur Rimbaud)

\section{Introducción}

Gilles Deleuze plantea una propuesta ética radical contra lo que llama «la obligación moral» (Deleuze, 2009: 27-41), entendida como un código normativo basado en la obediencia y en las pasiones tristes. Un producto envenenado resultado de la ignorancia y de la impotencia, del odio hacia nosotros mismos (la culpa) o hacia el otro, al que vemos como causante de nuestra tristeza. El esclavo, el tirano y el sacerdote son, nos dice Deleuze, las figuras que ejemplifican esta trinidad moralista. La ética, por el contrario, es la expresión de la potencia vital, de los seres humanos libres que se mueven por alegría y por amor. Desde este punto de partida spinoziano, actualizado por Deleuze, Pierre Hadot, Michel Foucault y François Jullien, formulan, a través de sus nociones respectivas de "ejercicio espiritual», «cuidado de sí» y «vivir existiendo", tres propuestas éticas de transformación de sí para autoconstituirse como sujeto ético y llevar una vida verdadera.

Pierre Hadot y Michel Foucault pertenecen a la misma generación de Deleuze, la nacida en la Francia de los años veinte, pero en lugar de buscar referentes en Spinoza lo hacen en la Antigüedad grecorromana. François Jullien, en cambio, nace en los años cincuenta. Está, por tanto, separado generacionalmente de los anteriores y busca sus referentes en la sabiduría china.

Pierre Hadot (1922-2010), como nos explica en el libro entrevista La filosofía como forma de vida (Hadot, 2009: 23-79) y en el artículo "Mis libros y mis estudios» (Hadot, 2006: 305-315), va perfilando progresivamente esta idea de filosofía como un ejercicio espiritual. Desde sus primeras lecturas y traducciones de la filosofía antigua, ya vislumbra que la filosofía tiene originariamente una función terapéutica, la de curar el alma, y que cada escuela propone, como remedio, una determinada forma de vida. La filosofía antigua no pretende construir un discurso sino una práctica, y los textos filosóficos son prescriptivos en la medida en que nos enseñan a vivir, que es su finalidad. Es una operación casi alquímica, valga la metáfora, porque opera como una conversión que nos transforma radicalmente. Se aprende a mirar el mundo tal como es, a pensarlo adecuadamente y a seguir una conducta justa. En todos 
los escritos de Pierre Hadot se va perfilando esta idea fundamental que guía sus lecturas, sus escritos y, sobre todo, su vida. Se trata de acceder a verdades que nos llevan a la superación del yo para abrirnos a una perspectiva Universal, que es, a la vez, Humana y Cósmica. Algunos modernos como Montaigne, Goethe $^{1}$, Thoureau o Wittgenstein mantienen esta idea de la filosofía como forma de vida.

Michel Foucault (1926-1984) mostraba una trayectoria biográfica y filosófica totalmente paralela a la de Hadot y todo hacía pensar que nunca coincidiría con él, pero en los últimos años dio un giro importante a sus investigaciones que le llevaron a un encuentro con Hadot ${ }^{2}$. Hasta entonces el sujeto era, para Foucault, una forma de sujeción. El efecto de la trama de los campos de saber y las relaciones de poder en que estaba inserto. Pero, a partir de los años ochenta, empieza a plantearse la posibilidad de entender el sujeto desde otra óptica, la de la autoconstitución ética como práctica de la libertad. Todo ello le hace dar un giro inesperado en la orientación de sus cursos en el Collège de France y en la orientación de los volúmenes segundo y tercero de su historia de la sexualidad, que quedan reorientados hacia un marco histórico diferente, el de las escuelas alejandrinas y romanas y la manera como estas abordan el arte de vivir (Foucault, 1987a, 1987b). Será en el curso de los primeros meses de 1982, La hermenéutica del sujeto, donde Foucault elabora su nueva concepción de la subjetivación como un posible camino de libertad donde es posible crear una estética de la existencia propia y singular (Foucault, 2005). Es aquí donde Foucault explicita la influencia que tuvo Pierre Hadot con su noción de la filosofía como ejercicio espiritual a partir de su lectura de los antiguos.

François Jullien (1951), por su parte, quiere cuestionar la filosofía de manera radical, para evidenciar y poder pensar lo más familiar, aquello de lo que no podemos distanciarnos porque está demasiado cerca. Esta idea le vincula a Foucault ${ }^{3}$. El proyecto solo es posible desde afuera de nuestra tradición y esto le lleva a China como concreción de nuestra alteridad. Consigue una beca en este país y empieza a estudiar la lengua y el pensamiento chinos. Pero el planteamiento de Jullien no es el de un sinólogo, es el de un filósofo. Se trata de salir de nuestra filosofía, es decir, de la tradición que arranca en Grecia y continúa en Europa, para retornar a ella a partir de lo que no ha pensado. Para hacerlo debe iniciar una especie de exilio intelectual desde una estrategia oblicua, un movimiento de ida y vuelta circular. En China no hay ni búsqueda de la verdad ni interrogantes ontológicos, hay otro camino de pensamiento. Esta sabiduría tradicional china permite a Jullien preguntarse por nuestra forma de

1. Uno de los últimos libros de Pierre Hadot, casi un testamento vital, es el extraordinario escrito No te olvides de vivir: Goethe y la tradición de los ejercicios espirituales (Hadot, 2010).

2. Para un análisis detallado y con todos los matices de las relaciones entre Pierre Hadot y Michel Foucault es importante leer el libro de Luis Roca Jusmet Ejercicios espirituales para materialistas: El diálogo (im)posible entre Pierre Hadot y Michel Foucault (Roca Jusmet, 2017).

3. François Jullien cita a Foucault como referencia en diversas ocasiones. 
vida, y a partir de este diálogo elabora una propuesta de otro modo de estar en el mundo, lo que llama «vivir existiendo» (Jullien, 2018). China le mostrará lo «impensado» de nuestra filosofía. De este diálogo aprenderá su manera de buscar una vida verdadera.

\section{Pierre Hadot: la filosofía como forma de vida}

La filosofía es, para Pierre Hadot, un conjunto de prácticas que él llama «ejercicios espirituales»: aprender a vivir, aprender a dialogar, aprender a morir y aprender a leer (Hadot, 2006). Aprender a vivir supone, de entrada, un trabajo sobre la atención, que es fundamental porque es el que nos hace mantener la actitud adecuada frente a cada situación vital, delante de cada problema concreto. Implica un estado de serenidad, una tranquilidad de ánimo que se combina con una actitud de alerta que nos permite estar siempre a la altura de las circunstancias. Supone, como defendía el estoicismo, saber diferenciar en cada momento lo que depende de nosotros y lo que no, que hemos de aceptar siempre. De lo que depende de nosotros hemos de seleccionar lo que es importante, que es lo que nos interpela a emprender una acción justa. Pero para cumplir con nuestro deber necesitamos tener siempre actualizados los principios éticos, lo que implica otro ejercicio complementario, que es el de la memorización comprensiva, ya que necesitamos tener presentes las reglas básicas de conducta. Esto es posible porque llevamos a cabo una tercera práctica, muy importante, que es la meditación permanente sobre nuestros principios y su interiorización en nuestra vida cotidiana ${ }^{4}$. Todo esto nos permite crear un margen de libertad con respecto a nuestro entorno, porque ser libre significa crear este espacio interno asumiendo los propios límites, aceptando lo imposible, sin vivirlo nunca como impotencia. Esto es lo que define la actitud y la posición de los hombres libres, la de los que han elegido no ser esclavos ni de los otros ni de sí mismos, es decir, de los automatismos de las propias pasiones. Se parte de la aceptación racional de la Unidad de todas las cosas, marcadas por un Logos ordenador que les da un sentido y en el que el filósofo aspira únicamente a la perfección moral. Está la formulación de lo que él llama «la triple disciplina del deseo, del juicio y de la acción». El alma es quien recibe las imágenes, a partir de las cuales forma un juicio desde el cual se genera un deseo. La física nos disciplina el deseo porque nos enseña a contemplar cada proceso desde la globalidad y desde el encadenamiento necesario de todas las cosas, nos hace entender que las cosas son lo que son y no pueden ni deben ser de otra manera. La consecuencia de lo anterior es el absurdo de «querer lo que no tenemos y nos gusta" $\mathrm{y}$ "no querer lo que tenemos y nos disgusta». También que lo que está al margen de lo bueno y lo malo, el resto de las cosas del mundo, debemos vivirlo con total indiferencia. Si entendemos todo esto, el deseo aparecerá únicamente como deseo del Bien, y la aversión, como recha-

4. Un libro extraordinario de Pierre Hadot donde profundiza sobre el tema es La ciudadela interior, dedicado a Marco Aurelio (Hadot, 2013). 
zo del Mal. La disciplina del juicio, la lógica, es el razonamiento que hacemos a partir de la contemplación que nos proporciona la Física: es el juicio objetivo, la capacidad de ver las cosas tal como son, sin distorsionarlas por las pasiones. Finalmente tenemos la disciplina de la acción a través de la Ética, es decir, intentar, con todos nuestros recursos, invertir el obstáculo y transformarlo en la oportunidad para una buena acción. Lo que importa es el mantenimiento de los principios, para lo cual es necesario todo un trabajo interior, que con firme autodisciplina nos conduce al dominio de las pasiones y a una actitud serena. Es la paradoja entre necesidad y libertad, la que muestra que, aunque todo está determinado, nuestra libertad forma parte de este proceso. Hadot, que se sabe moderno aunque admire a los antiguos, no quiere cerrarse a una escuela, quiere recoger lo mejor de cada una. Aunque se inspira en el estoicismo, también aprende del epicureísmo, que tiene la virtud de añadir a la opción estoica del deber su idea de gozo, de alegría. Pero, sobre todo, la irradiación de la figura de Sócrates como el modelo ejemplar del filósofo que no escribe nada y que transmite su filosofía a través de su propia vida y de su propia muerte $^{5}$. El primer filósofo moderno que impacta a Hadot es Montaigne, cuyos escritos tienen plenamente este aspecto práctico de la filosofía como arte de vida que se resume en una anécdota plenamente significativa. Cuando un amigo le comenta a Montaigne en una carta que no tiene nada que contarle porque no le ha pasado nada especial, la respuesta de Montaigne es genial: "¿Cómo? ¿No has vivido? Esta no es solo la fundamental, sino la más ilustre de las ocupaciones». En él destaca la importancia de centrarse en el presente, de vivirlo plenamente. Este es otro ejercicio fundamental para Hadot, el de vivir siempre en el presente, no en la nostalgia del pasado ni en la esperanza del futuro. Los antiguos, por supuesto, lo conocían muy bien y se expresaban de manera contundente en el carpe diem de Horacio. Una cuestión fundamental es huir de la fantasía, cuya función es negativa porque nos evade del presente hacia mundos imaginarios. Aprender a morir, que es como definía Platón la filosofía, es otro ejercicio espiritual fundamental para Pierre Hadot. Hay que ser fiel al Logos, lo cual quiere decir que hemos de ser capaces de correr el riesgo de perder la vida (como le pasó a Sócrates) por la virtud. Pero también quiere decir que hemos de ser conscientes de la finitud de la vida y aprovecharla. La lectura es, asimismo, para Hadot, un ejercicio espiritual fundamental, que consiste en saber detenernos, liberarnos de nuestras preocupaciones y replegarnos sobre nosotros mismos, dejando que los textos nos hablen mediante una inmersión en ellos para llegar a un estado de apertura al otro ${ }^{6}$. Leer es situarse en un difícil estado que oscila entre la no sabiduría y la sabiduría, entendiendo cuál es la intención del que escribe, y a partir de aquí podemos sopesar y valorar lo que dice. Antes de criticar hay que escuchar, esto lo enten-

5. En esta línea es interesante profundizar en el tema con la lectura de El arte de vivir: Reflexiones socráticas de Platón a Foucault (Nehamas, 2005).

6. Un excelente ensayo sobre el papel de la lectura en Pierre Hadot lo hace Antoni BoschVeciana con su libro El moviment lector de Pierre Hadot (Bosch-Veciana, 2013). 
dían muy bien los antiguos. La lectura nos lleva entonces a otro ejercicio espiritual que es el dialogar, que empieza siempre por saber escuchar al otro, por entender su lógica, un ejercicio practicado en común, que invita siempre a cada cual a examinar su conciencia, a dirigir la conciencia sobre sí mismo. El diálogo es un tipo de combate espiritual que cuestiona constantemente nuestros propios saberes y que tiene como función someterse al Logos, a la Verdad, ir hacia el Bien, como toda alma desea. La prueba de la filosofía es, entonces, la propia vida, nuestra práctica. Para Pierre Hadot, la filosofía es una forma de vida que nos hace mejores y más sabios. Viene a ser, por tanto, la vía para una vida verdadera.

\section{Michel Foucault: el cuidado de sí para otra vida}

En La hermenéutica del sujeto Michel Foucault elabora en profundidad su propuesta del cuidado de sí, y lo hace a partir de la enseñanza de las escuelas alejandrinas y romanas, especialmente el estoicismo (Foucault, 2005). Se trata de un trabajo de transformación de sí a través de unos ejercicios que nos permiten acceder a otra manera de vivir $^{7}$ y constituirnos como sujetos éticos en una práctica de la libertad incompatible con los estados de dominación. Sócrates es el iniciador de la propuesta de que hay que conocerse, pero para ocuparse de uno mismo. Es un combate para ser libre, contra las pasiones (a nivel interno) y contra las formas de dominio (a nivel externo). Un ejercicio importante es el de la vista desde lo alto, que consiste en salir de uno mismo para verse como parte del Cosmos, y de esta forma relativizar lo que nos ocurre. Un ejercicio inverso, pero complementario del anterior, es el análisis del contenido de las representaciones para comprobar que detrás de ellas no hay nada consistente. Otro de los ejercicios es el autoexamen, que comprende el matutino, a través del cual pensamos lo que haremos durante el día y cómo tenemos que hacerlo, y el examen vespertino, en el que se trata no solo de pensar lo que se ha hecho, sino también de compararlo con lo que teníamos que hacer, y si hay contradicción, entender por qué se ha fallado. Pero es importante que seamos conscientes de que esta práctica no tiene ni un carácter judicial (en el que uno se transforma en un juez de sí mismo) ni tampoco de castigo (de penitencia y de culpa, como en el del cristianismo). Por el contrario, se trata de una manera de buscar la eficacia en el arte del autodominio, que es básico en el arte de vivir. Hay también unos ejercicios que consisten en técnicas para controlar las representaciones mentales, de dominio del pensamiento a través de sus contenidos. Una práctica muy importante es la parresía, el coraje de decir la verdad ${ }^{8}$, que presenta tres dimensiones importantes. La primera es que

7. Un ensayo muy brillante y sugerente sobre el tema es el de Wilhelm Schmid (2002) titulado En busca de un nuevo arte de vivir: La pregunta por el fundamento y la nueva fundamentación de la ética de Foucault.

8. El tema de la parresía será el que dará una dimensión más política a esta última ética de Foucault. Será el hilo conductor de los dos últimos cursos en el Collège de France, posteriores al que nos ocupa (Foucault, 2011, 2014). 
lo que era inicialmente una guía de un maestro para el discípulo se va transformando cada vez más en un deber de uno sobre sí mismo; la segunda, que el principio de esta práctica es el conocimiento de uno mismo, y la tercera es que lo que está en juego no es el descubrimiento de las propias profundidades psíquicas, de su secreto, sino la relación de uno mismo con una serie de principios interiorizados.

Están también los ejercicios relacionados con la ética de la palabra: la escritura y la lectura. El primero es la escritura de sí, que consiste en un cuaderno de notas que los antiguos llamaban hypomnemata, una especie de memorial de cosas leídas, escuchadas o pensadas que merecen interés. Pero también un repaso de nuestras experiencias para valorar si se ajustan a nuestros principios. No para constituirnos en jueces de nosotros mismos, ni para plantear nada que tenga que ver con el pecado o la culpa, sino para hacer balance y mejorar aprendiendo. La lectura es el segundo ejercicio relacionado con la palabra, en el que cada libro tiene que ser una experiencia que integramos en nuestra vida y en nuestro proyecto singular. Otro ejercicio es la escucha. Vienen luego los ejercicios de meditación, el más importante de los cuales es el praemeditatio malorum, que se trata de una experiencia que consiste en imaginar la peor situación para habituarnos a ella, para prepararnos para soportarla con dignidad en el momento en que aparece. Su límite conduce finalmente a la meditación sobre la muerte, con la que damos un salto cualitativo, ya que al meditar sobre la muerte somos capaces de ver lo que somos: un cuerpo finito que se despliega como proceso, que lo hace en un tiempo que se acaba. La muerte es la conclusión de nuestra vida, la que de alguna manera le da un sentido, ya que la vida es finita y como tal hemos de quererla. Otro ejercicio interesante es el que propone Séneca: se trata de vivir cada jornada como si fuera toda la vida. Foucault citará algo que Hadot omite, que es la importancia de los ejercicios corporales, que no son los gimnásticos para fortalecer la musculatura o para embellecer el cuerpo., sino ejercicios respiratorios, suaves, para agilizar y dar fluidez al cuerpo y, a través de él, al alma. También la amistad es un ejercicio espiritual por recuperar, que señala de todas maneras las diferencias entre la manera griega de relacionarse entre amigos.

Este sujeto ético que defiende Foucault está en permanente construcción y siempre se muestra en combate contra sus dependencias y contra los poderes que quieren limitar su libertad. La misma noción de experiencia, como elemento central, nos hace ver que está en función también de una alteridad, de una relación con el otro, en una ontología de la relación que entiende la interioridad como una especie de pliegue. El sujeto es una forma, no una sustancia, y esta forma se va constituyendo durante la existencia de cada cual y en los encuentros y desencuentros con los otros. Propone hacer de la vida de cada cual un arte, una obra de arte. Foucault vuelve a los antiguos para aprender de ellos, no para repetirlos; se trata, en definitiva, de actualizarlos críticamente. No hay en Foucault una defensa nostálgica de lo que dicen los antiguos, ni él confía en encontrar en ellos un modelo para aplicar al presente. Foucault dice en varias ocasiones que los griegos y los romanos no vivían 
de manera ideal, que estaban llenos de prejuicios y de exclusiones. De lo que se trata es de reflexionar sobre los aspectos de su experiencia para aprender algo que nos pueda servir hoy, como una caja de herramientas para concretar un posible arte de vivir. La vida se entiende como una prueba, como una experiencia, como un reto a partir del cual podemos perfeccionarnos. El mundo se convierte en algo paradójico: por una parte, es un objeto de conocimiento y, por otro, es el lugar donde nos experimentamos como sujetos éticos a partir de la verdad.

\section{François Jullien: vivir existiendo}

François Jullien constata que cuando en China se aborda la cuestión de la buena vida no se plantea en términos de felicidad, puesto que es un concepto que en esta cultura ni siquiera se contempla. No se parte tampoco de una concepción dualista ni de preguntar por el sentido de la vida. Es algo más inmanente, ya que de lo que se trata es de lo que ellos llaman "nutrir la vida», es decir, ir a lo más básico, a las raíces vitales, donde no hay diferencia entre lo corporal y lo espiritual. Se trata de alimentar, de hacer circular el principio vital $(q i)$ y de evitar las obstrucciones, que están en el origen de las enfermedades. Hay que liberarse de la preocupación por la vida, a la que no hay que forzar ni controlar, ya que la vida es un proceso global y dinámico que se debe facilitar desde la espontaneidad. No es que tengamos un cuerpo, es que cuerpo, es decir un proceso estructurado de energía. Hay múltiples términos chinos, nos dice Jullien, para hablar de este cuerpo: xing (que sería la forma actual), $t i$ (el ser constituido), $q i$ (el aliento y la energía) y shen (la mente espíritu). Todos son matices de la misma realidad corporal en una concepción unitaria que es orgánica y funcional. Hay que buscar la larga vida, que para ellos está ligada a la buena vida: fluida, flexible, abierta, sin bloqueos. Vivir es como un proceso de maduración en el que hay que orientar bien la energía, sin dispersarse ni malgastarla. La noción griega y europea de felicidad, ausente de la sabiduría china, implica fijación y finalidad, mientras que lo que hace el sabio chino es desarrollar de manera natural, sin objetivo, las propias capacidades. Es el resultado no buscado el que cuenta, la consecución natural de una actitud sabia frente a la vida (Jullien, 2007), que consiste en ir hacia la armonía, que es un equilibrio dinámico autorregulado. El pensamiento chino es fundamentalmente estratégico, pero con una concepción de la eficacia basada en la idea de transformación a partir de una acción indirecta y oblicua (Jullien, 2010). No debemos forzar, ni controlar, hay que seguir la propensión de las cosas, aprovechar su potencial facilitando la orientación más favorable. No hay elección dramática, sino solo una adaptación al curso de las cosas de las que nosotros formamos parte buscando la energía potencial de cada situación. Se trata de obtener mucho efecto con poco esfuerzo, de adaptarse a las circunstancias recogiendo lo mejor para nosotros, facilitando lo que nos es favorable. No hay un plan establecido, porque lo que hay que hacer es estar alerta a lo que va pasando, evaluando las fuerzas que entran en juego. Si hay 
que actuar hay que hacerlo lo más pronto posible, antes de que el proceso se estructure, modificar lo blando antes de que se vuelva rígido. La racionalidad china se establece sobre la base de la relación entre condición y consecuencia, mientras que la occidental lo hace entre medios y fines, en términos de cálculo y de éxito o fracaso, de victoria o derrota. En el lado griego, origen del europeo, el estratega es como un piloto de barco que navega en alta mar para llegar a su destino venciendo las amenazas imprevistas. Es la epopeya y lo heroico en una narración dramatizada. En la lógica china todo es condicional y complejo, y nosotros formamos parte de un proceso que nunca se cierra, que siempre está abierto a nuevas combinaciones. $\mathrm{Al}$ mismo tiempo es importante también la idea del vacío necesario: no hay que llenar nada del todo ni llenarlo todo, sino que hay que dejar siempre un margen, un espacio vacío. La referencia china es la agricultura y las estaciones, que son un tiempo cualitativo. No hay que tirar de las plantas para que crezcan más rápido, hay que facilitar su crecimiento separando todo lo que traba su desarrollo. Importa la eficacia de la inmanencia, que es la de adaptarse a los procesos, no el de trascenderlos para imponer un objetivo. Hay que intentar vencer sin enfrentarse, prevenir el conflicto antes de que aparezca. Con la sabiduría china se capta la vida como un proceso que madura ofreciendo una consecuencia, que es la buena cosecha. En Un sabio no tiene ideas (2001) Jullien trata específicamente el tema del tiempo como elemento de una filosofía de vida. En la lengua china no hay tiempos verbales, el ser es siempre un ser en fase y la noción básica es la de duración. El tema del tiempo vuelve a ser retomado en su libro sobre las transformaciones silenciosas (2010), que plantea que el cambio no es lo que se manifiesta cuando hay una ruptura aparente, sino que es la consecuencia del cambio lento que provoca un giro sutil, casi imperceptible y que puede llegar incluso a invertir la situación. Lo que hay es una emergencia visible de un largo proceso invisible. La misma relación entre la causa y el efecto se diluye en este planteamiento, ya que hay que referirse a la duración y a lo global, con todos los factores condicionantes, para entender lo que pasa. El envejecimiento no es ni decadencia ni degradación, sino un elemento más del proceso de vivir. La muerte no es una ruptura, sino una consecuencia más de la vida. No hay ni drama cristiano ni tragedia griega, ni tan solo la melancólica heroicidad del romanticismo. Lo que importa no es lo extraordinario del acontecimiento nuevo, sino la persistencia de lo ordinario. Es como las estaciones, que se transforman las unas en las otras sin un límite estricto que señale su separación. El sabio chino no tiene ideas (Jullien, 2001), porque sabe que cualquier visión es parcial y lo que quiere es estar abierto al conjunto sin distorsionarlo con prejuicios...

En el ensayo Vivir existiendo: Una nueva ética (Jullien, 2018), el filósofo conducirá todo lo que ha aprendido en su diálogo con China a una propuesta ética de transformación de sí que implica un trabajo interno que consiste en establecer una distancia con respecto a lo que llama «nuestra superficie de adherencia", aquello más primario a lo que estamos adheridos. Se trata de tener la capacidad de decidir sobre aquello a lo que investimos de afecto, de deseo. 
La libertad es, en cierta forma, la capacidad de romper estos automatismos tan primarios, de soltar amarras, pero también la de investir de una manera ligera, sin dependencias, lo que puede alimentarnos. Está también la necesidad de resistir, entendiendo de manera dialéctica el valor de la negación que abre el camino de lo posible. Evitar estancarse, empantanarse en la inercia, en la rutina. Aquí aprendemos a captar tanto el giro que conduce al estancamiento como el que nos sacará de él. Esto se da, la mayoría de las veces, en el marco de las transformaciones silenciosas (Jullien, 2010). Pero a veces parece aparecer como una ruptura, sea como principio o como fin, lo cual no deja de ser una ilusión, porque el inicio es también resultado de un proceso del que emerge, al igual que el final lo es de algo que se va deshaciendo. Vivir significa transformar el duro deseo de durar y existir en potencia vital. Para ello hay que des-coincidir con uno mismo ${ }^{9}$, no identificarse con una autoimagen. La duración se mantiene por su proceso continuado de renovación, de actualización de la energía. Des-coincidir quiere decir 'no identificarse, no fijarse, mantener el espíritu abierto'. Ciertamente, hay que vivir en el aquí y en el ahora, lo que no comporta entenderlo como hacerlo en el instante, sino experimentarlo como un proceso, ya que nuestro presente es este paso permanente del futuro al pasado. Vivir en la inmanencia de este mundo, de este todo del que formamos parte, que se verifica directamente en la experiencia y el aprendizaje que resulta de ella.

François Jullien continúa esta conceptualización en lo que él llama «una segunda vida" (Jullien, 2017), que se refiere al paso que hay de la vida a la existencia. El punto de partida es inmanentista: solo tenemos una vida, de la que no hay recambio, de la que no podemos salir y volver a entrar. Tampoco es el resultado del acto voluntarista de una reinvención, sino la consecuencia de una maduración, de la transformación silenciosa a que nos aboca la propia experiencia, de la lucidez que vamos adquiriendo con la elaboración de lo vivido, que nos aparta de las ilusiones, del trabajo continuado sobre uno mismo. No es el resultado espontáneo de la vejez, sino el giro que adquirimos de esta voluntad de «vivir existiendo». La segunda vida viene a ser el buen «invierno» de nuestra vida si nos hemos preparado para que sea así. Todo ello concluye en lo que él llama «la verdadera vida».

\section{Construir un sujeto ético para "una vida verdadera"}

Estas tres propuestas siguen un mismo hilo conductor, que es el del proyecto de poner la filosofía al servicio de la emancipación ética, de un sujeto que puede realizar una vida verdadera. Pierre Hadot nos recuerda que la filosofía, entendida como forma de vida, es una educación para adultos. Su problema central, planteado desde Sócrates, es «¿cómo vivir?». Se trata de una pregunta que se plantea el adulto cuando quiere vivir de otra manera, no siguiendo lo

9. El tema de la des-coincidencia es fundamental en esta etapa de Jullien. A él está dedicado su libro Dé-coincidence: D’où viennent l'art et l'existence? (Jullien, 2017). 
que marca la sociedad (Hadot, 2019: 179-188). «De otra manera» quiere decir 'de una manera verdadera, desde un perfeccionamiento ético, superando los límites del propio yo, abriéndose a lo Universal de la Humanidad y el cosmos'. Michel Foucault acaba reivindicando aquello a lo que nos invitaba Kant, en el siglo xviII, en su texto ¿Qué es la ilustración? Lo recupera justamente para reivindicar al sujeto capaz de autorizarse a sí mismo, que supera su minoría de edad y que ya no necesita un guía espiritual (Foucault, 2011: 31-45). Vemos, en definitiva, cómo estos dos filósofos contemporáneos, desde formaciones y referencias diferentes, nos invitan a construirnos como sujetos éticos y a vivir una verdadera vida, lo cual no deja de ser una alternativa, desde la profundidad y la apuesta por la libertad que hace el trabajo filosófico, a las soluciones fáciles del mercado de la autoayuda ${ }^{10}$ y a las ilusiones neoliberales de entender la vida como una empresa ${ }^{11}$, ya que, como dijo el gran filósofo Baruch Spinoza:

Si la vía que, según he mostrado, conduce a este logro parece muy ardua, es posible hallarla, sin embargo. $Y$ arduo es, ciertamente, debe ser lo que tan raramente se encuentra. En efecto: si la salvación estuviera al alcance de la mano y pudiera conseguirse sin gran trabajo, ¿cómo podría suceder que casi todos la ignoren? Pero todo lo excelso es tan difícil como raro. (Spinoza, 1994: 379)

Pero lo que resulta interesante es también lo que François Jullien aportará a este debate entre Pierre Hadot y Michel Foucault. Lo cierto es que será Foucault quien se acercará a Hadot cuando dará un giro a principios de los ochenta y se interesará por lo que puede aportar la filosofía antigua (sobre todo las escuelas helenístico-romanas) a su teoría de la subjetivación y a la posibilidad de construirnos como sujetos éticos. Se interesará por la visión de Hadot del sentido originario de la filosofía como ejercicio espiritual o forma de vida. Se iniciará entre ellos una breve relación, pero la muerte prematura e inesperada de Foucault malogrará el diálogo. Pierre Hadot dejará claros sus acuerdos y desacuerdos con Foucault (Hadot, 2006: 251-257), aunque lo que acaba dejando de manifiesto son, sobre todo, las diferencias (Hadot, 2006: 265-275). Hubiera sido interesante saber la respuesta de Foucault y, ya que no pudo hacerlo, podemos imaginar por dónde hubieran ido (Roca Jusmet, 2017: 105117). Pero lo que nos sugiere François Jullien, aunque lo aplique en otro contexto (el de Grecia y Europa en relación con China), es sustituir la noción de diferencia por la de distancia. No se trata entonces de comparar un planteamiento con otro (y que nos conduce siempre a la diferencia), sino de buscar la posibilidad de establecer puentes desde la distancia. Pierre Hadot y Michel Foucault presentan dos trayectorias totalmente paralelas en las que no hay convergencia posible (Roca Jusmet, 2017: 19-49). La salida es, entonces, crear puentes que puedan complementarlas, en lugar de dejarlas separadas o forzar

10. Edgar Cabanas y Eva Illouz hacen un agudo análisis en su libro Happycracia: Cómo la ciencia y la industria de la felicidad controlan nuestras vidas (Cabanas e Illouz, 2019).

11. Para una genealogía de la idea neoliberal de entender la vida como una empresa es muy interesante el análisis de Francisco Vázquez García en Tras la autoestima: Variaciones sobre el yo expresivo en la modernidad tardía (Vázquez García, 2012). 
encuentros artificiosos. El puente puede establecerse a partir del tratamiento de lo Universal que plantea Hadot y el de lo singular que formula Foucault. Abrirse a lo Universal significa salir de los límites del yo narcisista para abrirse a la Humanidad, que es lo común con el resto de humanos y una perspectiva cósmica en la que nos sentimos parte del Cosmos. Cuando Michel Foucault plantea la necesidad de llevar una estética de la existencia, de convertir la propia vida en una obra de arte, no lo hace para desarrollar este yo narcisista que cuestiona Hadot. Por el contrario, lo que plantea Foucault es potenciar la parte más singular, más propia, para desde ella abrirse a los otros y, por qué no, también al Cosmos.

La segunda aportación que realiza François Jullien es la de conceptualizar esta vida construida desde el sujeto ético como «una vida verdadera». Esta noción de "vida verdadera» podemos considerar que está implícita en Pierre Hadot, ya que para él lo que hace la filosofía es una conversión (Hadot, 2006: 177-191), es decir, una transformación del sujeto por la verdad que repercute en la manera de percibir, de desear, de pensar y de actuar, es decir, de vivir. Todo ello lo concreta de forma magistral en su estudio de Marco Aurelio, que sería un paradigma de «vida verdadera» (Hadot, 2013). En el caso de Michel Foucault su conceptualización de "vida verdadera» aparece en su último curso del Collège de France: El coraje de la verdad: El gobierno de si y de los otros (Foucault, 2014). Aquí es donde Michel Foucault continúa trabajando el tema de la parresía y desplaza su interés de los estoicos a los cínicos. Aquí habla de una vida verdadera en este mundo de acuerdo con una verdad ética elegida. A diferencia del cristianismo, es un ascetismo que no promete otro mundo ni se basa en la obediencia. Es una ascesis que invita a la construcción de sí como sujeto de una vida verdadera, es decir, en conformidad con la alteridad de un entorno que se va construyendo en la ruptura y la transgresión, contra los mecanismos de normalización.

Lo que aporta es una conceptualización no sobre el tipo de prácticas o de ejercicios, sino de su consecuencia de llevarlas a cabo. Digo "consecuencia» y no «resultado» recogiendo la diferencia que establece Jullien entre la planificación tal como se entiende en Europa y lo que surge del proceso de transformaciones silenciosas tal como se plantea en China. Defiende aquí, por tanto, la idea de eficacia tal como se propone desde la tradición de la sabiduría china (Jullien, 1999). François Jullien quiere llegar a un momento de concluir, después del instante de ver lo que se pensaba en China y del tiempo de comprender sobre lo que puede ser esta verdadera vida, que inicialmente llamó «vivir existiendo» (2018) y luego, «una segunda vida» (2019). Integra igualmente su conceptualización de la des-coincidencia (2018), que le lleva a entender este vivir existiendo como un vivir en la contradicción, en un proceso abierto que nunca es igual a sí mismo, en el que siempre hay una tensión de opuestos que equilibrar. Es un decir «no» a la inercia, a la rutina, «al ir tirando», a la vida banal. No se trata, entonces, de aspirar a otra vida idealizada, no es perderse en ilusiones ni buscar momentos extraordinarios (Jullien, 2020). La vida puede ser otra desde el realismo, desde la singularidad del individuo y desde una ética 
que nos lleve a una vida digna de ser vivida. No es propiamente una conversión (aquí se distancia totalmente de Hadot y algo de Foucault), sino el darse cuenta de que frente a nuestra vida normalizada se abre la posibilidad de otra vida más propia (aquí se reencuentra con Foucault). Aparece entonces la descoincidencia con la vida que vivimos y se abre una alternativa que vamos sacando de nuestra experiencia más propia y que tampoco podemos identificar con la sabiduría, ni con una vida buena, bella y feliz (se distancia de Hadot). Se trata de experimentar que nuestra vida no es una vida perdida, que es una vida realizada, que no es una vida alienada, sino que, mejor o peor, es nuestra vida. No es algo que conseguimos, sino un querer, un procurar vivir, un mantenernos a flote, un no renunciar, un mantener el combate. Quizás el mejor final sea el recuerdo de lo que dijo Antonio Machado: «Caminante no hay camino, se hace camino al andar». Este caminante que no acepta que le digan por donde debe ir es quizás el que se va construyendo como sujeto ético y es capaz de experimentar "una verdadera vida».

\section{Referencias bibliográficas}

Bosch-Veciana, Antoni (2013). El moviment lector de Pierre Hadot. Barcelona: AEAU.

Cabanas, Edgar e Illouz, Eva (2019). Happycracia: Cómo la ciencia y la industria de la felicidad controlan nuestras vidas. Barcelona: Paidós.

Deleuze, Gilles (2009). Spinoza: Filosofía práctica. Barcelona: Tusquets.

ERIBOn, Didier (2004). Michel Foucault. Barcelona: Anagrama.

Foucault, Michel (1987a). Historia de la sexualidad 2: El uso de los placeres. Ciudad de México: Siglo XXI.

- (1987b). Historia de la sexualidad 3: La inquietud de sí. Ciudad de México: Siglo XXI.

- (2005). La hermenéutica del sujeto. Madrid: Akal.

- (2011). El gobierno de si y de los otros. Madrid: Akal.

- (2014). El coraje de la verdad: El gobierno de sí y de los otros, II. Madrid: Akal.

НаDот, Pierre (2006). Ejercicios espirituales y filosofia antigua. Madrid: Siruela.

- (2009). La filosofía como forma de vida. Barcelona: Alpha Decay.

- (2010). No te olvides de vivir: Goethe y la tradición de los ejercicios espirituales. Madrid: Siruela.

- (2013). La ciudadela interior. Barcelona: Alpha Delcay.

- (2019). La philosophie comme éducation des adultes: Textes, perspectives, entretien. París: Librairie Philosophique J. Vrin.

Jullien, François (1999). Tratado de la eficacia. Madrid: Siruela.

- (2001). Un sabio no tiene ideas. Madrid: Siruela.

- (2005). Del «tiempo»: Elementos para una filosofía del vivir. Madrid: Arena Libros.

- (2007). Nutrir su vida: Más allá de la felicidad. Buenos Aires: Katz.

- (2010). Las transformaciones silenciosas. Barcelona: Ediciones Bellaterra. 
- (2017). Dé-coüncidence: D’où viennent l'art et l'existence? París: Le Livre de Poche.

- (2018). Vivir existiendo: Una nueva ética. Buenos Aires: El Cuenco de Plata.

- (2019). Une seconde vie. París: Le Livre de Poche.

- (2020). De la vraie vie. París: Éditions de l'Observatoire.

Nehamas, Alexander (2005). El arte de vivir: Reflexiones socráticas de Platón a Foucault. Valencia: Pre-Textos.

Roca Jusmet, Luis (2017). Ejercicios espirituales para materialistas: El diálogo (im)posible entre Pierre Hadot y Michel Foucault. Barcelona: Terra Ignota.

Schmid, Wilhem (2002). En busca de un nuevo arte de vivir: La pregunta por el fundamento y la nueva fundamentación de la ética de Foucault. Valencia: Pretextos.

SPINOZA, Baruch (1994). Ética. Madrid: Alianza Editorial.

VÁzQuez García, Francisco (2012). Tras la autoestima: Variaciones sobre el yo expresivo en la modernidad tardía. Donostia: Tercera Prensa.

Luis Roca Jusmet (Barcelona, 1954) es investigador de la filosofía en relación con el cuidado de sí y la ética como práctica de la libertad. Ha escrito Redes y obstáculos (Editorial Club Universitario, 2010) y Ejercicios espirituales para materialistas. El diálogo (im)posible entre Pierre Hadot y Michel Foucault (Terra Ignota Ediciones, 2017). También ha publicado muchos artículos en libros y revistas sobre esta problemática.

Luis Roca Jusmet (Barcelona, 1954) is a researcher of philosophy relating to care of the self and ethics as a practice of freedom. He has written Networks and Obstacles (Editorial Club Universitario, 2010) and Spiritual Exercises for Materialists. The (im) possible dialogue between Pierre Hadot and Michel Foucault (Terra Ignota Ediciones, 2017). He has also published many articles in books and magazines on this issue. 